$\underline{\mathbf{P}-150}$

\title{
Constituents from the Stems of Malaysian Uncaria Tomentosa
}

\author{
Nor Haslini Wahid, Zainon Mohd Noor, Shamsul Khamis and Rohaya Ahmad* \\ Faculty of Applied Sciences, Universiti Teknologi MARA, 40450 Shah Alam Selangor; \\ E-mail: rohayaahmad@salam.uitm.edu.my
}

Uncaria tomentosa (Willd. ex Schult.) DC. is well known as a medicinal plant that has been used for various treatments. This tronical vine grows un to $30 \mathrm{~m}$ tall and commonlv found in natural forest. It has hook-like thorns that resemble the claws of a cat. The leaves are elliptic with a smooth edge, and grow in opposite whorls of two. Although there has not been any literature found on the availability of this species locally, we have discovered it in several parts of Peninsular Malaysia. A preliminary investigation of the stems of the plant has yielded three compounds, scopoletin, pteropodine and isopteropodine along with $\beta$-sitosterol. The structures of the isolated compounds were characterized by analysis of spectral characteristics (mostly 1D, 2D NMR and mass spectrometry) and comparison with literature.

Keywords: Uncaria tomentosa, scopoletin, pteropodine, isopteropodine, $\beta$-sitosterol. 